\title{
Acute dose of MDMA (75 mg) impairs spatial memory for location but leaves contextual processing of visuospatial information unaffected
}

Received: 4 November 2005 / Accepted: 9 January 2006 / Published online: 1 March 2006

C) Springer-Verlag 2006

\begin{abstract}
Rationale: Research concerning spatial memory in 3,4-methylenedioxymethamphetamine (MDMA) users has presented conflicting results showing either the presence or absence of spatial memory deficits. Two factors may have confounded results in abstinent users: memory task characteristics and polydrug use. Objectives: The present study aims to assess whether a single dose of MDMA affects spatial memory performance during intoxication and withdrawal phase and whether spatial memory performance after MDMA is task dependent. Materials and methods: Eighteen recreational MDMA users participated in a doubleblind, placebo-controlled, three-way crossover design. They were treated with placebo, MDMA $75 \mathrm{mg}$, and methylphenidate $20 \mathrm{mg}$. Memory tests were conducted between 1.5 and $2 \mathrm{~h}$ (intoxication phase) and between 25.5 and $26 \mathrm{~h}$ (withdrawal phase) post-dosing. Two spatial memory tasks of varying complexity were used that required either storage of stimulus location alone (spatial memory task) or memory for location as well as processing of content or contextual information (change blindness task). Results: After a single dose of MDMA, the subjects made larger localization errors and responded faster compared to placebo in the simple spatial memory task during intoxication phase. Inaccuracy was not due to increased response speed, as determined by regression analysis. Performance in the change blindness task was not affected by MDMA. Methylphenidate did not affect performance on any of the tasks. Conclusion: It is concluded that a single dose of MDMA impairs spatial memory for location but leaves processing of contextual information intact.
\end{abstract}

K. P. C. Kuypers $(\bowtie) \cdot$ J. G. Ramaekers Experimental Psychopharmacology Unit,

Department of Neurocognition, Faculty of Psychology, Maastricht University,

Maastricht, The Netherlands

Present Address:

K. P. C. Kuypers

P.O. Box 616, 6200 MD Maastricht, The Netherlands
Keywords MDMA - Spatial · Memory · Task-complexity $\cdot$ Acute $\cdot$ Methylphenidate

\section{Introduction}

3,4-Methylenedioxymethamphetamine (MDMA, Ecstasy) has been frequently associated with cognitive impairments in abstinent and/or current Ecstasy users and more particularly with problems in verbal memory (Cole and Sumnall 2003; Parrott 2001). Research concerning spatial memory in MDMA users, however, has provided mixed results showing either the presence or absence of spatial memory deficits. It has been suggested that this discrepancy may be primarily related to the types of spatial memory task that have been employed in these studies and that tasks requiring predominantly memory storage would be less vulnerable for MDMA than spatial memory tasks requiring storage as well as contextual processing of visuospatial cues (Wareing et al. 2004). However, there is little support for this notion when classifying spatial memory studies according to three distinguishable types of task.

First, there are studies using spatial span tasks in which subjects are required to repeat a previously seen or heard (Wareing et al. 2000) sequence, sometimes in combination with a visual decision task (Wareing et al. 2004, 2005). Some between-group comparisons have revealed impairment of spatial memory in Ecstasy polydrug users compared to polydrug or nondrug controls (Verkes et al. 2001; Wareing et al. 2004, 2005), whereas others did not (Morgan 1998; Gouzoulis Mayfrank et al. 2000; Wareing et al. 2000, 2004, 2005). A second category includes studies using "delayed matching to sample tasks" or recognition tasks. In this type of task, the subject is required to compare a previously seen pattern or location with one that is shown after a certain delay and to respond by stating whether these two are the same or not. Some studies have found Ecstasy polydrug users to be impaired on this kind of tasks, as compared to a polydrug control group (Verkes et al. 2001; Fox et al. 2001), whereas others did not (McCann et al. 1999; Semple et al. 1999). Fox et al. (2002) also reported conflicting results on delayed 
matching to sample tasks. The third category comprises studies using "search tokens tasks". In this type of task, subjects are required to find hidden objects, one at a time, in an increasing number of boxes. Once a token or object is found in a certain place during one trial, the subject has to keep in mind not to return to that place. Fox et al. (2002) demonstrated that Ecstasy users performed worse on this task, on the most difficult level, as compared to normal controls, but this finding conflicted with results from an earlier study (Semple et al. 1999). In other words, categorization of spatial memory tasks has not yet provided additional insight into the conflicting pattern of spatial memory deficits that has emerged in studies employing current and/or abstinent drug users.

Yet, the importance of task classifications may become more apparent when another confounding factor common to most studies in MDMA users can be controlled for, that is polydrug use. It is well known that MDMA users also consume a variety of other drugs, most notably cannabis, alcohol, and cocaine (Scholey et al. 2004; Rodgers et al. 2001). All of these drugs have been associated with cognitive deficits (Dafters et al. 2004; Verdejo Garcia et al. 2005), which in turn may have confounded results from studies on spatial memory function in MDMA users. One way to circumvent the problem of drug confounding is to study the effects of MDMA on spatial memory in a placebocontrolled, double-blind study that checks for and excludes concurrent drug use during memory testing by means of drug screening in blood or urine.

The present study is a double-blind, placebo-controlled study that aims to assess whether a single dose of MDMA affects spatial memory performance during the intoxication and withdrawal phase and whether spatial memory performance after MDMA is task dependent. Two spatial memory tasks of varying complexity were used that required either storage of stimulus location alone (spatial memory task) or memory for location as well as processing of content or contextual information (change blindness task). Methylphenidate (Ritalin), a dopamine transporter blocker, was used as active control to see whether the effects of MDMA were mediated by dopamine and/or serotonin. Data presented here were part of a larger study on the acute effects of MDMA on memory and cognition. Some of its results showing a direct pharmacological link between verbal memory impairment and acute MDMA administration have been published elsewhere (Kuypers and Ramaekers 2005).

\section{Materials and methods}

\section{Design and treatments}

The study design was double-blind, placebo-controlled, three-way crossover, with balancing of the treatments. Testing took place on two consecutive days, in three separate testing periods, with a minimum washout period of 14 days in between. On the first day of each period, participants received either $75 \mathrm{mg}$ of MDMA, $20 \mathrm{mg}$ of methylphenidate, or placebo. MDMA powder was dissolved in $25 \mathrm{ml}$ bitter orange peel syrup and mixed with $200 \mathrm{ml}$ orange juice, and methylphenidate was administered as a pill. All treatments were identical in appearance. Participants received on each first day a solution and a pill to blind them and the researcher for the treatment. The second day was identical to the first day with the exception that no drugs or placebo were given.

\section{Participants}

Twenty-eight volunteers underwent medical examination. Three volunteers were excluded from participation as they did not meet inclusion or exclusion criteria. The remaining subjects passed the medical screening and entered the study. Seven subjects dropped-out prematurely either because of private matters (three cases) or because of repeated failure to abstain from drug use in between testing days as indicated by drug urine screens on test days (four cases). Eighteen subjects, nine male and nine female, aged in the range of 20 to 39 years [mean (SD) 26.22 (5.1)] completed all study treatments. They all had used MDMA before onset of the study. Lifetime use of MDMA varied from light $(<30$ times $)$ in 15 subjects to heavy (between 60 and 120 times) in three subjects. They were recruited by means of advertisements in local newspapers and the snowball technique. Potential candidates first underwent a telephonic screening. They were questioned about their drug use and medical condition and were given information about the study. They were sent a detailed brochure with information about the study procedure and two questionnaires for medical history and detailed history of drug use. Inclusion criteria were experience with MDMA use, free from psychotropic medication, good physical health, absence of major medical endocrine and neurological conditions, and normal weight (BMI 18-28 kg/ $\mathrm{m}^{2}$ ). Exclusion criteria were history of drug abuse (other than MDMA) or addiction, pregnancy or lactation, cardiovascular abnormalities [assessed by a standard 12 lead electrocardiogram (ECG)], excessive drinking ( $>20$ alcoholic consumptions), hypertension (diastolic $>100$, systolic $>170$ ), and history of psychiatric or neurological disorders. A medical doctor checked the completed list and, upon approval, the subjects were invited for a medical examination. Blood and urine samples were taken for examination and they underwent an electrocardiogram measurement. When they were found to be medically sound, they were contacted for participation. They were given a brochure with information about the study and a number of rules they had to obey during the period of the study and were made to sign an informed consent to prove that they read the information and agreed on it. They were paid upon completion of the testing periods for their participation. The study was performed in accordance with the 1975 declaration of Helsinki, adjusted in Edinburgh (2000), and approved by the Medical Ethics Committee of the Academic Hospital of Maastricht and the University of Maastricht. A permit for obtaining, storing, and administering MDMA was obtained from the Dutch drug enforcement administration. 
Study procedure

Before testing days, participants were familiarized with the tests on a training day. Participants were requested to abstain from any drug use 1 week before the medical examination until 14 days after the last testing day. They were asked not to use any caffeinated or alcoholic beverages $24 \mathrm{~h}$ before testing and to get a normal night's sleep. Subjects were allowed to smoke but the amount of cigarettes was limited to two during the whole testing period and smoking was not allowed right before cognitive testing.

Participants were screened for alcohol use in breath and for recent drug use in urine (THC/opiates/cocaine/amphetamines/methamphetamines) upon arrival at the testing facilities at 9 A.M. Women were given a pregnancy test. When the results on all of the tests were negative, the subjects proceeded with a light breakfast and were given a sleeping questionnaire to assess sleep complaints. One hour later, subjects received drugs or placebo. One hour and a half after drug intake, a blood sample was taken to determine the MDMA/MDA or ritalinic acid concentrations in blood plasma. After blood sampling, subjects proceeded with the memory tests during the intoxication phase. Similar study procedures were followed when the subjects returned to the laboratory the following day to assess memory performance during withdrawal, i.e., between 25.5 and $26 \mathrm{~h}$ post-dosing. An additional blood sample was taken every 11 th day after drug administration to control for renal and liver functioning. Subjects were instructed to report any adverse physical reactions that they might experience during drug intoxication. No serious adverse reactions emerged.

\section{Cognitive measures}

Spatial memory task The spatial memory task (Vermeeren et al. 1995) assesses short-term memory for spatial information. The subject is briefly shown a fixation point in the center of the computer screen. Shortly thereafter, a target appears at a random location for $500 \mathrm{~ms}$. The subjects' task is to memorize the location of the target and, using a computer mouse, to relocate the cursor as accurately as possible over that position. The cursor appears either immediately upon target offset or after a delay of 2 or $4 \mathrm{~s}$. The subject depresses the left mouse button to indicate that the cursor is at the recalled position of the target. The test consists of 75 trials, divided equally among the three response delays. The sequence of delays is random. Dependent variables are localization error and reaction time.

Change blindness task The change blindness task (Dornhoefer et al. 2002) assesses visual scene analysis and memory for changes in visuospatial information. The subject is presented a series of 100 photographs of traffic situations. Each photograph is shown for $3 \mathrm{~s}$ and followed by a 300-ms blank screen. During the blank period, a fixation dot appears that subjects have to attend to. In the next $3 \mathrm{~s}$, the original photo reappears with or without a superimposed change in the traffic scene. Changes appear in $80 \%$ of the cases and half of those are either relevant or irrelevant to traffic (context of change). Fifty percent of the relevant and irrelevant changes occur at a position central or peripheral (location of change) relative to the position of the fixation dot during the blank period. Number of correct detections and reaction time are the dependent variables.

\section{Pharmacokinetics}

Blood samples were collected in 5-ml glass tubes containing sodium fluoride and potassium oxalate. After centrifugation at $4,000 \times \mathrm{g}$ for $10 \mathrm{~min}$, the resultant plasma was transferred to a clean tube and frozen at $-20^{\circ} \mathrm{C}$ until liquid chromatography-mass spectrometry (MS)/MS analysis. The limit of quantification for MDMA, MDA, and ritalinic acid was $1 \mathrm{ng} / \mathrm{ml}$.

\section{Statistical analyses}

All statistical analyses were conducted by means of SPSS 11.5 for Windows. Each objective parameter was analyzed using GLM univariate repeated-measures procedures with treatment (three levels) and day of testing (two levels) as main within-subject factors. Additional factors were response delay (three levels) in the spatial memory task and context of change (two levels) and location of change (two levels) in the change blindness task. Separate contrast (drug vs placebo) tests were conducted in case of a significant overall effect of treatment or treatment by day. The alpha criterion level of significance was set at $p=0.05$.

\section{Results}

Spatial memory task ANOVA revealed significant main effects of treatment by day $\left(F_{2,34}=3.46, p=0.043\right)$ and response delay $\left(F_{2,34}=83.56, p<0.001\right)$ on localization error. The latter effect reflects increasing localization error as a function of response delay (Fig. 1). The former effect was further analyzed by means of separate drug placebo contrasts on each day of testing. These revealed that MDMA significantly increased localization error on day $1\left(F_{1,17}=10.86\right.$,

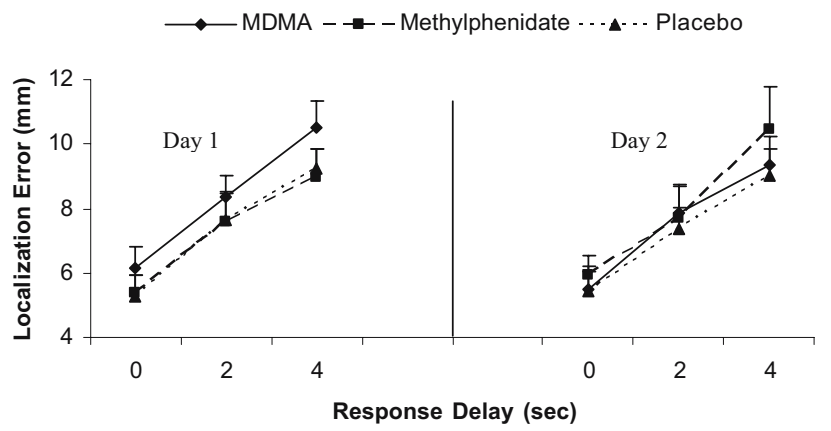

Fig. 1 Mean (SE) localization error (mm), per response delay, for each drug condition on both test days 


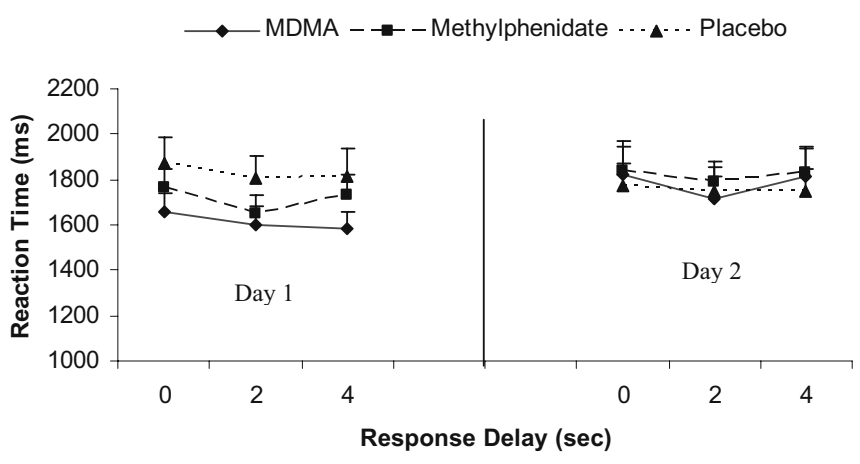

Fig. 2 Mean (SE) reaction time (ms), per response delay, for each drug condition on both test days

$p=0.004)$ as compared to placebo. No differences in localization error were apparent between drugs and placebo on day 2.

Reaction time showed significant main effects of drug by day $\left(F_{2,34}=6.44, p=0.004\right)$, day $\left(F_{1,17}=.46, p=0.050\right)$, and response delay $\left(F_{2,34}=3.42, p=0.044\right)$ (Fig. 2$)$. The interaction effect was further analyzed by means of separate drug placebo contrasts on each day of testing. These showed that MDMA significantly reduced reaction time on day 1 $\left(F_{1,17}=7.92, p=0.012\right)$ as compared to placebo. No differences in reaction time were apparent between drugs and placebo on day 2.

An additional multiple linear regression analysis was conducted to determine whether other factors independently correlated with localization error in the spatial memory task. The regression analysis was conducted on individual trial data rather than the subject means to achieve maximal statistical power. Each repetition of the spatial memory tests generated 75 individual trials. The total number of trials that entered the equation was determined by the number of subjects $\times$ the number of treatments $x$ the number of individual trials in each spatial memory test repetition. Selected factors were reaction time, drug (MDMA or placebo) response delay, trial number, and localization error. Results showed a significant positive correlation of the factors drug and response delay with localization error. Together, these two factors significantly explained about $8 \%\left(R=0.289, R^{2}=0.083\right)$ of the variance in localization error $\left(F_{3,2699}=102.846, p<0.001\right)$. Reaction time was not correlated with localization error (Table 1$)$.

Change blindness task Reaction time performance in the change blindness task revealed overall effects of context of change (relevant vs irrelevant) $\left(F_{1,17}=184.01\right.$, $p<0.001$ ), location of change (central vs peripheral) $\left(F_{1,17}=51.15, \quad p<0.001\right)$, and day $\left(F_{1,17}=23.55\right.$, $p<0.001)$. Number of correct detections was affected by context of change $\left(F_{1,17}=674.34, p<0.001\right)$, location of change $\left(F_{1,17}=42.46, p<0.001\right)$, and day $\left(F_{1,17}=23.55\right.$, $p<0.001$ ) (Table 2). Changes relevant to traffic safety or driver performance were faster and more often detected than changes irrelevant to traffic. Changes in the central field of vision were faster and more frequently discovered than changes taking place in the peripheral field. Treatments did not affect performance. Interactions between treatments and content or location of change also failed to reach statistical significance.

\section{Pharmacokinetics}

Plasma concentrations of MDMA, MDA, and ritalinic acid were determined 1.5 (day 1) and $25.5 \mathrm{~h}$ (day 2) post-drug administration. Concentrations of MDMA were on average

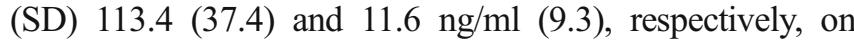
days 1 and 2. Concentrations of MDA were on average 2.9 (0.9) and $2.1 \mathrm{ng} / \mathrm{ml}$ (1.2), respectively, on days 1 and 2.

Table 1 Summary of means (SE) and treatment by day interaction effects in the spatial memory task (overall $d f=2,34)$

\begin{tabular}{|c|c|c|c|c|c|c|c|c|}
\hline \multirow{3}{*}{$\begin{array}{l}\text { Dependent } \\
\text { variables }\end{array}$} & \multirow{3}{*}{$\begin{array}{l}\text { Delay } \\
\text { (s) }\end{array}$} & \multirow[t]{3}{*}{ Day } & \multirow[t]{3}{*}{ Treatments } & \multirow[b]{3}{*}{ Methylphenidate } & \multirow[b]{3}{*}{ Placebo } & \multicolumn{3}{|l|}{ ANOVA } \\
\hline & & & & & & $\begin{array}{l}\text { Overall } \\
\text { (treatment } \\
\text { by day) }\end{array}$ & \multicolumn{2}{|l|}{ Contrasts } \\
\hline & & & & & & $F \quad \mathrm{p}$ & $\begin{array}{l}\text { MDMA vs } \\
\text { placebo }\end{array}$ & $\begin{array}{l}\text { Methylphenidate vs } \\
\text { placebo }\end{array}$ \\
\hline \multirow{6}{*}{$\begin{array}{l}\text { Localization } \\
\text { error }\end{array}$} & 0 & 1 & $6.14(0.67)$ & $5.39(0.53)$ & $5.28(0.65)$ & \multirow[t]{6}{*}{3.460 .043} & \multirow[t]{3}{*}{0.004} & \multirow[t]{3}{*}{-} \\
\hline & 2 & & $8.36(0.66)$ & $7.59(0.88)$ & $7.63(0.90)$ & & & \\
\hline & 4 & & $10.49(0.84)$ & $8.96(0.88)$ & $9.21(0.64)$ & & & \\
\hline & 0 & \multirow[t]{3}{*}{2} & $5.51(0.69)$ & $5.94(0.58)$ & $5.43(0.63)$ & & \multirow[t]{3}{*}{-} & \multirow[t]{3}{*}{-} \\
\hline & 2 & & $7.86(0.88)$ & $7.67(1.01)$ & $7.36(0.69)$ & & & \\
\hline & 4 & & $9.34(0.91)$ & $10.46(1.32)$ & $9.01(0.82)$ & & & \\
\hline \multirow[t]{6}{*}{ Reaction time } & 0 & \multirow[t]{3}{*}{1} & $1659.67(77.70)$ & $1762.11(88.12)$ & $1867.28(117.29)$ & \multirow[t]{6}{*}{6.440 .004} & \multirow[t]{3}{*}{0.012} & \multirow[t]{3}{*}{-} \\
\hline & 2 & & $1602.66(83.44)$ & $1652.11(75.72)$ & $1803.72(98.16)$ & & & \\
\hline & 4 & & $1586.83(69.02)$ & $1734.50(85.23)$ & $1816.06(120.25)$ & & & \\
\hline & 0 & \multirow[t]{3}{*}{2} & $1822.67(119.50)$ & $1842.44(124.50)$ & $1772.56(99.89)$ & & \multirow[t]{3}{*}{-} & \multirow[t]{3}{*}{-} \\
\hline & 2 & & $1715.44(96.52)$ & $1789.78(92.26)$ & $1748.22(103.34)$ & & & \\
\hline & 4 & & $1813.44(123.83)$ & $1828.89(116.11)$ & $1747.78(100.06)$ & & & \\
\hline
\end{tabular}


Table 2 Summary of means (SE) and treatment by day interaction effects in the change blindness task (overall $d f=2,34)$

\begin{tabular}{|c|c|c|c|c|c|c|c|c|}
\hline \multirow[t]{2}{*}{ Dependent variables } & \multirow[t]{2}{*}{ Day } & \multirow[t]{2}{*}{ Context of change } & \multirow[t]{2}{*}{ Location of change } & \multirow[t]{2}{*}{ Treatments } & \multirow[b]{2}{*}{ Methylphenidate } & \multirow[b]{2}{*}{ Placebo } & \multicolumn{2}{|c|}{$\begin{array}{l}\text { ANOVA } \\
\text { Overall (treatment } \\
\text { by day) }\end{array}$} \\
\hline & & & & & & & $F$ & $\mathrm{p}$ \\
\hline \multirow[t]{8}{*}{ \# correct } & \multirow[t]{4}{*}{1} & \multirow[t]{2}{*}{ Irrelevant } & Central & $9.83(0.94)$ & $9.67(0.78)$ & $10.11(1.09)$ & \multirow[t]{8}{*}{0.23} & \multirow[t]{8}{*}{ ns } \\
\hline & & & Peripheral & $8.83(0.55)$ & $8.11(0.66)$ & $8.06(0.50)$ & & \\
\hline & & Relevant & Central & $15.94(0.47)$ & $15.94(0.45)$ & $15.33(0.52)$ & & \\
\hline & & & Peripheral & $15.89(0.59)$ & $16.61(0.30)$ & $16.39(0.33)$ & & \\
\hline & \multirow[t]{4}{*}{2} & \multirow[t]{2}{*}{ Irrelevant } & Central & $10.00(0.44)$ & $10.50(0.47)$ & $9.78(0.67)$ & & \\
\hline & & & Peripheral & $9.39(0.69)$ & $9.33(0.40)$ & $9.39(0.73)$ & & \\
\hline & & \multirow[t]{2}{*}{ Relevant } & Central & $17.56(0.33)$ & $17.22(0.31)$ & $17.44(0.37)$ & & \\
\hline & & & Peripheral & $16.61(0.32)$ & $15.56(0.47)$ & $16.11(0.39)$ & & \\
\hline \multirow[t]{8}{*}{ Reaction time } & \multirow[t]{4}{*}{1} & \multirow[t]{2}{*}{ Irrelevant } & Central & $893.80(66.81)$ & $922.29(53.75)$ & $982.74(81.68)$ & \multirow{8}{*}{ ) } & \multirow[t]{8}{*}{ ns } \\
\hline & & & Peripheral & $998.71(66.22)$ & 998.79 (56.64) & $967.27(51.56)$ & & \\
\hline & & \multirow[t]{2}{*}{ Relevant } & Central & $658.64(27.81)$ & $681.80(27.10)$ & $723.90(43.24)$ & & \\
\hline & & & Peripheral & $756.58(29.73)$ & $766.57(37.58)$ & $822.92(38.48)$ & & \\
\hline & \multirow[t]{4}{*}{2} & \multirow[t]{2}{*}{ Irrelevant } & Central & $835.76(51.79)$ & $851.43(57.43)$ & $780.00(41.08)$ & & \\
\hline & & & Peripheral & $976.19(53.24)$ & $1004.49(54.66)$ & $929.80(51.46)$ & & \\
\hline & & \multirow[t]{2}{*}{ Relevant } & Central & $620.81(36.52)$ & $681.56(38.42)$ & $658.29(39.64)$ & & \\
\hline & & & Peripheral & $783.91(30.76)$ & $779.38(41.08)$ & $825.20(53.22)$ & & \\
\hline
\end{tabular}

$n s$ Not significant

Concentrations of ritalinic acid were on average 95.9 (78.4) and $22.9 \mathrm{ng} / \mathrm{ml}(7)$, respectively, on days 1 and 2.

\section{Discussion}

An analysis of variance revealed that a single dose of MDMA caused subjects to perform worse on a simple spatial memory task during the intoxication phase. Subjects displayed larger localization errors and responded faster while under influence of MDMA. These effects were no longer visible during the withdrawal phase. To sort out whether changes in reaction time had contributed significantly to changes in localization error during MDMA intoxication, a multiple linear regression was conducted. It showed that localization error was not correlated with reaction time. MDMA treatment and response delay, however, were correlated and explained about $8 \%$ of the variance in localization error. Results from ANOVA and multiple regression together indicate that MDMA is the primary factor underlying spatial memory impairment in the present study.

Contextual processing of visuospatial information in the change blindness task was not affected by treatment. Overall, changes relevant to traffic safety or driver performance were faster and more often detected than changes irrelevant to traffic. Changes in the central field of vision were faster and more frequently discovered than changes taking place in the peripheral field. However, spatial memory for changes in location or context was not affected by treatment. This seems to suggest that processing of information conveyed through a variety of spatial locations is not impaired during MDMA intoxication. An alternative explanation, however, might be that the change blindness task is not sensitive to drug effects.
This cannot be totally excluded as this was the first study to apply a change blindness paradigm in a drug trial. However, the task was sufficiently sensitive to pick up on internal task manipulations (i.e., content of change and location of change), which indicates that the task is sensitive to external manipulation such as drug treatment as well. In sum, a single dose of MDMA impaired memory for location in a simple spatial memory task but did not affect processing of contextual information in a complex visuospatial memory task.

The absence of effects of the dopamine transporter blocker (methylphenidate) on performance is interesting. It indicates that MDMA's effect on spatial memory is not due to its action within the dopaminergic system. Though MDMA exerts its effects in the brain through a multitude of transmitter systems, it is generally assumed that MDMA induced memory deficits that are related to changes in serotonergic function (Bolla et al. 1998; McCann et al. 1994; Reneman et al. 2002; Verkes et al. 2001). The present data seem to support this general notion. Our data are also in line with results from a study of Luciana et al. (1998) who assessed the effects of a 5HT agonist in a similar spatial memory paradigm as in the current study. Localization error increased after administering fenfluramine, a 5HT agonist. This increased inaccuracy was not due to effects on motor performance, as indicated by the absence of a drug effect on latency. Our results mimic those of Luciana in that we also found increased inaccuracy independent of motor performance. These results together strengthen the notion that 5HT suppletion after serotonergic drugs such as MDMA and fenfluramine produces spatial memory impairment. In addition, support for this serotonin hypothesis also comes from animal studies that have shown impairment of spatial memory after treatment with MDMA (Sprague et al. 2003; 
Broening et al. 2001) or $d$-fenfluramine (Morford et al. 2002) as well. Sprague et al. (2003) subsequently linked the MDMA-induced serotonergic lesions in the hippocampus to deficits seen in spatial memory. The overall conclusion that can be drawn from these animal studies is that 5HT plays a direct or indirect role in the observed deficits in spatial memory after treatment with a 5HT agonist or MDMA.

Other researches studying the effects of methylphenidate on spatial memory performance, however, have shown memory performance improvement in young healthy volunteers (Elliott et al. 1997; Mehta et al. 2000). Elliott et al. (1997) showed that methylphenidate $(20$ and $40 \mathrm{mg}) \mathrm{im}-$ proved performance on a spatial span task and a search tokens task as compared to placebo, when the methylphenidate session preceded placebo sessions. These facilitating effects of the drug were determined by the familiarity with the task (novelty of the task) and consequently only showed when subjects received methylphenidate on the first session. Mehta et al. (2000) showed that the size of effect of methylphenidate $(40 \mathrm{mg})$ on spatial memory correlated negatively with the baseline working memory capacity. This capacity was determined by performance on a span task, before administration of the drug. Subjects with lower working memory capacity showed the most improvement on a search tokens test in a positron emission tomography scanner after administration of methylphenidate as illustrated by a reduction in 'between search' errors and task-related reductions in $\mathrm{rCBF}$ when on methylphenidate. When comparing the results of these studies with the present results, a few comments can be made. First, cognitive tasks used in the present study were abundantly trained before testing took place so, in contrast to subjects in the study by Elliott et al. (1997), subjects were already familiar with the tasks. Second, it is likely that the working memory capacity of our subjects was rather high as shown by their excellent performance on the two spatial tasks during placebo treatment. Performance may have been close to maximal, leaving little space for measuring performance improvement when on methylphenidate. Third, both studies used another paradigm than the one used in the present study. A study mentioned earlier by Luciana et al. (1998) showed improvement of performance on the same task as used in the present study, after administration of a dopaminergic agent, bromocriptine. This improvement in performance was only visible after a long memory delay of $8 \mathrm{~s}$ and not at smaller memory delays as employed in the present study.

It is noteworthy that spatial memory performance during placebo treatment as well as during MDMA withdrawal was close to maximal in the present study. Subjects in the present study were generally light recreational users of MDMA, which may explain why their spatial memory performance appears relatively well as compared to some of the memory deficits that have been reported in abstinent users (Cole and Sumnall 2003; Parrott 2001). Studies in abstinent users usually employ light users as well as heavy users of MDMA. Long-term deficits during abstinence have repeatedly been associated with heavy MDMA use and may not have developed in light recreational users of MDMA as in the present study. The present data, therefore, cannot be taken to suggest that persisting spatial memory deficits will never occur during abstinence.

It is concluded that a single dose of MDMA impairs spatial memory for location in a simple spatial memory task but leaves processing of contextual visuospatial information in a more complex task intact.

Acknowledgements We would like to thank Nele Samyn, Gert De Boeck, and Marleen Laloup from NICC, Brussels for analyzing MDMA and methylphenidate blood plasma samples. We also would like to thank Pieter Unema for providing the pictures for the change blindness task and Philippe Bonny, Mark Jansen, and Anita van Oers for their contribution to this study. This study was part of the IMMORTAL project, funded by the EU grant GMA1-2000-27043.

\section{References}

Bolla KI, McCann UD, Ricaurte GA (1998) Memory impairment in abstinent MDMA ("Ecstasy") users. Neurology 51:1532-1537

Broening HW, Morford LL, Inman Wood SL, Fukumura M, Vorhees CV (2001) 3,4-Methylenedioxymethamphetamine (ecstasy)-induced learning and memory impairments depend on the age of exposure during early development. J Neurosci $21: 3228-3235$

Cole JC, Sumnall HR (2003) Altered states: the clinical effects of ecstasy. Pharmacol Ther 98:35-58

Dafters RI, Hoshi R, Talbot AC (2004) Contribution of cannabis and MDMA ("ecstasy") to cognitive changes in long-term polydrug users. Psychopharmacology 173:405-410

Dornhoefer SM, Unema PJ, Velichkovsky BM (2002) Blinks, blanks and saccades: how blind we really are for relevant visual events. Prog Brain Res 140:119-131

Elliott R, Sahakian BJ, Matthews K, Bannerjea A, Rimmer J, Robbins TW (1997) Effects of methylphenidate on spatial working memory and planning in healthy young adults. Psychopharmacology 131:196-206

Fox HC, McLean A, Turner JJ, Parrott AC, Rogers R, Sahakian BJ (2002) Neuropsychological evidence of a relatively selective profile of temporal dysfunction in drug-free MDMA ("ecstasy") polydrug users. Psychopharmacology 162:203-214

Fox HC, Parrott AC, Turner JJ (2001) Ecstasy use: cognitive deficits related to dosage rather than self-reported problematic use of the drug. J Psychopharmacol (Oxf) 15:273-281

Gouzoulis Mayfrank E, Daumann J, Tuchtenhagen F, Pelz S, Becker S, Kunert HJ, Fimm B, Sass H (2000) Impaired cognitive performance in drug free users of recreational ecstasy (MDMA). J Neurol Neurosurg Psychiatry 68:719-725

Kuypers KP, Ramaekers JG (2005) Transient memory impairment after acute dose of $75 \mathrm{mg}$ 3,4-methylene-dioxymethamphetamine. J Psychopharmacol (Oxf) 19:633-639

Luciana M, Collins PF, Depue RA (1998) Opposing roles for dopamine and serotonin in the modulation of human spatial working memory functions. Cereb Cortex (NY, NY 1991) $8: 218-226$

McCann UD, Mertl M, Eligulashvili V, Ricaurte GA (1999) Cognitive performance in $(+/-)$ 3,4-methylenedioxymethamphetamine (MDMA, "ecstasy") users: a controlled study. Psychopharmacology 143:417-425

McCann UD, Ridenour A, Shaham Y, Ricaurte GA (1994) Serotonin neurotoxicity after (+/-)3,4-methylenedioxymethamphetamine (MDMA; "Ecstasy"): a controlled study in humans. Neuropsychopharmacology 10:129-138 
Mehta MA, Owen AM, Sahakian BJ, Mavaddat N, Pickard JD, Robbins TW (2000) Methylphenidate enhances working memory by modulating discrete frontal and parietal lobe regions in the human brain. J Neurosci 20:Rc65

Morford LL, Inman Wood SL, Gudelsky GA, Williams MT, Vorhees CV (2002) Impaired spatial and sequential learning in rats treated neonatally with D-fenfluramine. Eur J Neurosci $16: 491-500$

Morgan MJ (1998) Recreational use of "ecstasy" (MDMA) is associated with elevated impulsivity. Neuropsychopharmacology 19:252-264

Parrott AC (2001) Human psychopharmacology of Ecstasy (MDMA): a review of 15 years of empirical research. Human Psychopharmacol 16:557-577

Reneman L, Endert E, de Bruin K, Lavalaye J, Feenstra MG, de Wolff FA, Booij J (2002) The acute and chronic effects of MDMA ("ecstasy") on cortical 5-HT2A receptors in rat and human brain. Neuropsychopharmacology 26:387-396

Rodgers J, Buchanan T, Scholey AB, Heffernan TM, Ling J, Parrott A (2001) Differential effects of Ecstasy and cannabis on self-reports of memory ability: a web-based study. Vol. 16:619-625 URLJ: http://www.interscience.wiley.com/jpages/0885-6222/

Scholey AB, Parrott AC, Buchanan T, Heffernan TM, Ling J, Rodgers J (2004) Increased intensity of Ecstasy and polydrug usage in the more experienced recreational Ecstasy/MDMA users: a WWW study. Addict Behav 29:743-752

Semple DM, Ebmeier KP, Glabus MF, O'Carroll RE, Johnstone EC (1999) Reduced in vivo binding to the serotonin transporter in the cerebral cortex of MDMA ('ecstasy') users. Br J Psychiatry 175:63-69
Sprague JE, Preston AS, Leifheit M, Woodside B (2003) Hippocampal serotonergic damage induced by MDMA (ecstasy): effects on spatial learning. Physiol Behav 79:281-287

Verdejo Garcia AJ, Lopez Torrecillas F, Aguilar de Arcos F, Perez Garcia M (2005) Differential effects of MDMA, cocaine, and cannabis use severity on distinctive components of the executive functions in polysubstance users: a multiple regression analysis. Addict Behav 30:89-101

Verkes RJ, Gijsman HJ, Pieters MS, Schoemaker RC, de Visser S, Kuijpers M, Pennings EJ, de Bruin D, Van de Wijngaart G, Van Gerven JM, Cohen AF (2001) Cognitive performance and serotonergic function in users of ecstasy. Psychopharmacology 153:196-202

Vermeeren A, Jackson JL, Muntjewerff ND, Quint PJ, Harrison EM, O'Hanlon JF (1995) Comparison of acute alprazolam $(0.25$, 0.50 and $1.0 \mathrm{mg}$ ) effects versus those of lorazepam $2 \mathrm{mg}$ and placebo on memory in healthy volunteers using laboratory and telephone tests. Psychopharmacology 118:1-9

Wareing M, Fisk JE, Murphy P, Montgomery C (2005) Visuo-spatial working memory deficits in current and former users of MDMA ('ecstasy'). Hum Psychopharmacol 20:115-123

Wareing M, Fisk JE, Murphy PN (2000) Working memory deficits in current and previous users of MDMA ('ecstasy'). $\mathrm{Br}$ J Psychol 91:181-188

Wareing M, Murphy PN, Fisk JE (2004) Visuospatial memory impairments in users of MDMA ('ecstasy'). Psychopharmacology $173: 391-397$ 